\title{
Experimental and Numerical Validation of Selective Weakening Retrofit for Existing Non-Ductile R.C. Frames
}

\author{
W. Y. Kam ${ }^{1}$ and S. Pampanin ${ }^{2}$ \\ Department of Civil and Natural Resources Engineering, University of Canterbury, \\ Private Bag 4800, Christchurch 8140, New Zealand. \\ ${ }^{1}$ Doctoral Candidate, email: wyk10@student.canterbury.ac.nz \\ ${ }^{2}$ Associate Professor, email: stefano.pampanin@ canterbury.ac.nz
}

\begin{abstract}
The development of cheap, whilst effective and relatively non-invasive structural retrofit techniques for existing non-ductile reinforced concrete (RC) structures still remains the most challenging issue for a wide implementation on a macro scale. Seismic retrofit is too often being confused as purely structural strengthening. As part of a six-years national project on "Seismic retrofit solutions for NZ multi-storey building", focus has been given at the University of Canterbury on the development of a counter-intuitive retrofit strategy for earthquake vulnerable existing rc frame, based on a "selective weakening" (SW) approach. After an overview of the SW concept, this paper presents the experimental and numerical validation of a SW retrofit strategy for earthquake vulnerable existing $\mathrm{RC}$ frame with particular focus on the exterior beam-column (b-c) joints. The exterior b-c joint is a critically vulnerable region in many existing pre-1970s RC frames. By selectively weakening the beam by cutting the bottom longitudinal reinforcements and/or adding external pre-stressing to the b-c joint, a more desirable inelastic mechanism can be attained, leading to improved global seismic performance. The so-called SW retrofit is implemented on four 2/3-scaled exterior RC b-c joint subassemblies, tested under quasi-static cyclic loading at the University of Canterbury. Complemented by refined 3D Finite Element (FE) models and dynamic time-history analyses results, the experimental results have shown the potential of a simple and cost-effective yet structurally efficient structural rehabilitation technique. The research also demonstrated the potential of advanced 3D fracture-mechanics-based microplane concrete modelling for refined $\mathrm{FE}$ analysis of non-ductile $\mathrm{RC}$ b-c joints.
\end{abstract}

Keyword: Selective weakening, seismic retrofit / rehabilitation, concrete beamcolumn joint, modelling concrete,

\subsection{INTRODUCTION AND STATEMENT OF PROBLEM}

The recent publications of technical guidelines [11, 22], FEMA 356 pre-standard [10] and international standards (Eurocode8-Part 3 [8] the ASCE-SEI 41 standard[2]) represent significant progress and address crucial needs in seismic rehabilitation and retrofit for modern urban society. It is widely recognised that poorly detailed nonductile reinforced concrete $(\mathrm{RC})$ moment-resisting frames pose significant risks to urban population in seismic zones. Research on the seismic performance of pre- 
1970s (prior to modern seismic codes) or non-ductile, mostly gravity-only designed, rc frame at sub-assemblies levels $[3,4]$ as well as at a large-scale frames level $[5,6]$ have shown the importance of robust and strong b-c connections in collapse prevention. The poor joint behaviour of older construction can be attributed to: the inadequate shear reinforcement in joint region, the poor bond properties of plain round bars reinforcement, the deficient anchorage details into the joint region and the lack of capacity design consideration.

In resolving this seismic deficiency of non-ductile rc frames, various seismic rehabilitation solutions have been proposed in the past and implemented with success for RC b-c joints $[2,11,22]$. However, the issue of cheap, effective and non-invasive structural retrofit techniques still remain the most challenging aspect of a retrofit intervention. This research is motivated by the need for an economical, low-invasive and low-technology structural retrofit solution that can be widely implemented. In particular, this research focuses on structural intervention on the exterior beamcolumn (b-c) joints of RC frames. It has been proposed that by adopting a partial retrofit intervention $[26,27]$, where only the exterior b-c joints are retrofitted, the soft-storey collapse of RC frames can be prevented while accepting some damage in the interior joints and columns.

In this contribution, the authors are presenting a counter-intuitive strategy for the seismic rehabilitation of RC frame structures, referred as "Selective Weakening"(SW) retrofit $[18,25]$. The paper will first introduce the concept of SW for a partial retrofit intervention on non-ductile RC frames. Then, the experimental results and numerical validation of SW retrofit for non-ductile exterior RC b-c joint are presented. This research is part of a larger research program on the development of seismic retrofit solutions for multi-story buildings in New Zealand [12].

\subsection{SELECTIVE WEAKENING FOR RETROFIT: CONCEPT}

\subsection{Existing retrofit strategies and techniques for RC frames}

For pre-1970s non-ductile RC frames, global or local strengthening (Figure 1a) has been and still remains the most popular retrofit strategy, particularly when dealing with ordinary buildings. While adding brace frames or shear walls (infilling or new) may certainly lead to a more structurally efficient super-structure (irrespectively of the suggestion for low- invasiveness promoted by the architects), proper engineering evaluation of the consequences of the overall scheme is crucial. Such strengtheningonly global retrofit might generate failures elsewhere within the overall structural system such as the foundation, whose strengthening costs and effort are definitely not negligible.

Local strengthening of critical elements and components such as steel, concrete or fibre-reinforced polymers (FRPs) jacketing have also shown tremendous potential, though the labour intensity and invasiveness of these retrofit techniques might still be a deterrent to their widespread application. Alternatively, for high-value and/or high importance structures, either privately or publicly owned, the reduction of seismic demand by means of supplemental damping (Figure 1b) and/or use of base isolation system (Figure 1c) has been regular practice, as these allows higher performance 
levels while being less intrusive. Again, the issue of cost and time/space invasiveness of these common techniques has been the reason for its limited application into private and ordinary buildings. Conceptually, all these common retrofit strategies are illustrated in Figure 1(a-c) within an Acceleration-Displacement Response Spectrum (ADRS) domain.

\subsection{Selective weakening retrofit and partial retrofit intervention for $\mathrm{RC}$ frames}

The final aim of the proposed intervention is to improve the inelastic mechanism of the overall frame, changing it from a joint shear or column failures, which could in turn lead to a sort of soft storey collapse, to a more ductile beam-sway mechanism relying on beam flexural hinging. This would improve the deformation capacity of the seismic resisting system, while protecting the weakest links of the super-structure as well as sub-structure (foundation).

The SW retrofit approach for b-c joints can be viewed conceptually in Figure 1d and e, where the weakened beam would be the new fuse ("or weakest link of the chain" according to the capacity design principles by Park and Paulay [29]) within the retrofitted b-c joints - hence attracting lower force $\left(\mathrm{S}_{\mathrm{A}}\right)$ demand and requiring higher displacement $\left(\mathrm{S}_{\mathrm{D}}\right)$ capacity.

Philosophically, SW retrofit strategy requires a paradigm shift for seismic rehabilitation, where deformation capacity and demand are prioritised and specific/critical structural (or non-structural) elements are weakened or strengthened to achieve the overall global objective of non-collapse and limited damage. Weakening and then strengthening (using post-tensioning) also allow the control of desired strength, thus protecting the foundations and other shear-failure sensitive elements within the structure itself.

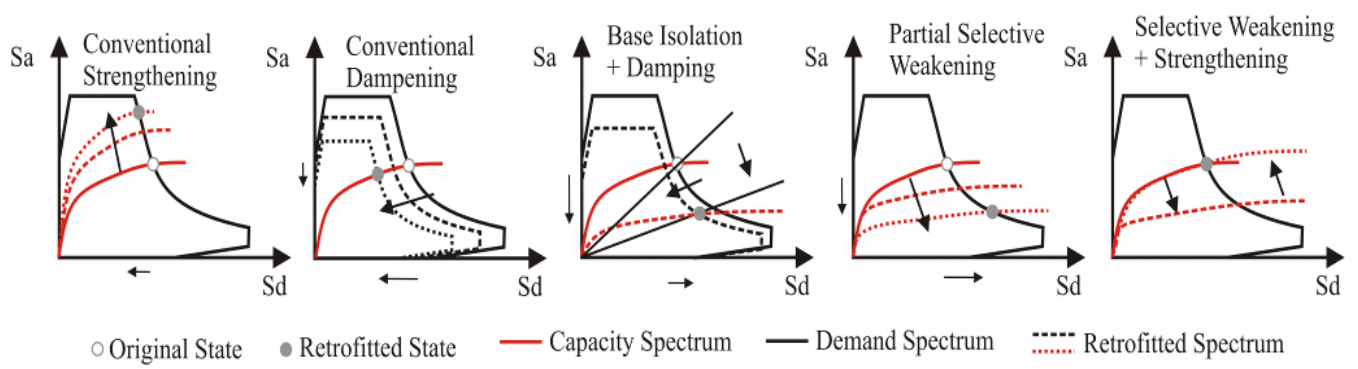

Figure 1: Acceleration-Displacement Response Spectrum (ADRS) illustration of different retrofit strategies a) strengthening b) added damping c) base isolation d) weakening only e) full selective weakening (weakening + strengthening)

A more illustrative example of the application of SW retrofit for non-ductile RC frame building is given in Figure 2. By inducing a flexural hinge in the beams by cutting some (or all) of the longitudinal beam reinforcement at the exterior b-c joint face, the overall frame, whilst weakened, becomes more ductile - thus achieving a higher deformation capacity. Further strengthening with external post-tensioning can improve the lateral capacity (to the desired limit) and energy dissipation while still 
achieving a greater deformation capacity. By adopting a displacement-based retrofit approach, the SW retrofit strategy would become more rationale and clearer.

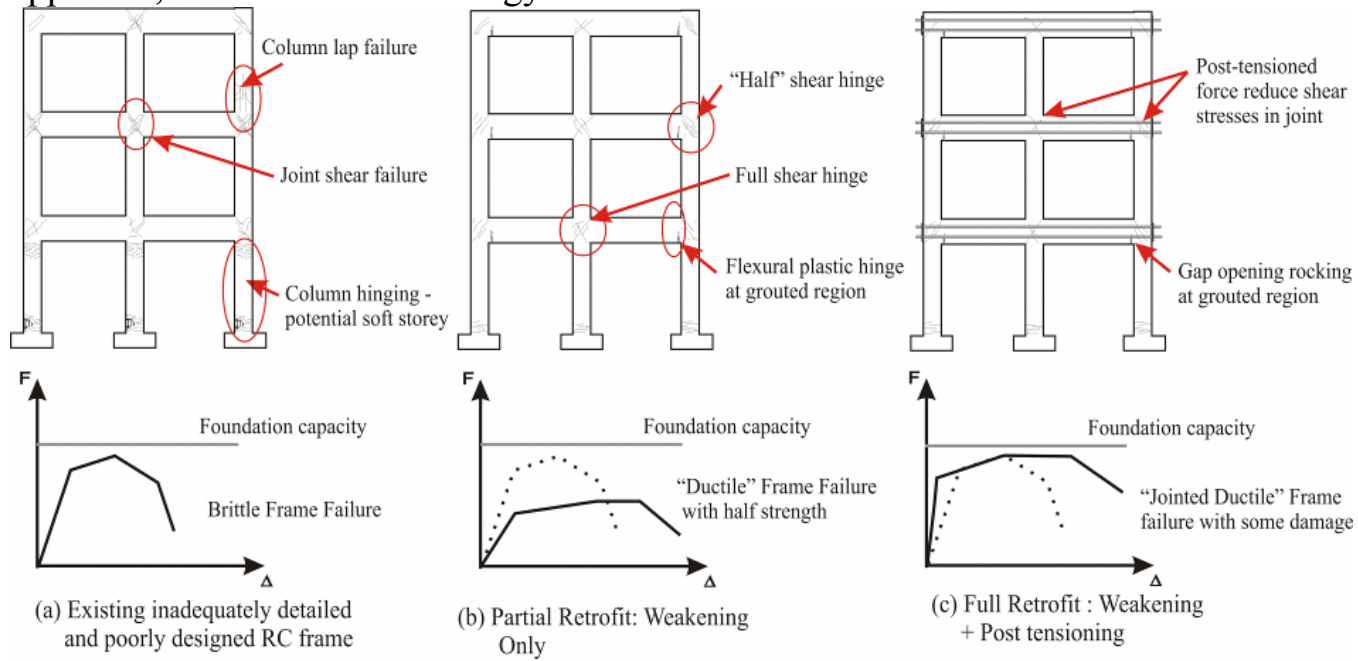

Figure 2: SW retrofit for RC frame: a) Non-ductile RC frame b) Beam weakeningonly retrofit c) Beam weakening and external post-tensioning of joint retrofit

\subsection{Existing literature on Selective Weakening Retrofit}

Selective Weakening (SW) Retrofit involves selectively weakening and upgrading certain elements of the structural system to achieve the required hierarchy of strength and deformation capacity. ATC-SEI 41 [2] gives "local modification of components" as one of the seismic rehabilitation strategies and within the commentary of the concrete subsection (6.4.2.5), external post-tensioning of joint and selective material removal from existing elements (viz. beam weakening) are both listed as rehabilitation measures. In NZ, for design of new RC structures using the NZ Concrete Standards [21], joint shear capacity can be improved by joint pre-stressing. However, the NZ seismic rehabilitation guidelines [22] only provides passing mention of external post-tensioning for retrofit of flexural elements.

Research [25] at the University of Canterbury has further developed the concept of SW retrofit, suggested by FEMA 356 [10], with complete experimental and numerical validation for the retrofit of shear-dominated structural wall [15] and hollowcore floor seating connection [16]. Following this latter research, the use of SW retrofit has also been adopted in the recent NZ building authority's guidelines on design, assessment and retrofit precast hollowcore floors [31]. Next, Kam et.al. [18] explored the idea of SW retrofit for RC frames and exterior b-c joints, and presented some promising analytical results (extended in Section 4.0).

The novelties in the retrofit strategy and solutions developed at Canterbury include 1) SW retrofit to target a rocking \& dissipative connection (thus emulating the behaviour of the emerging self-centering systems), and 2) SW retrofit to weaken and strengthen to a desirable strength threshold (thus protecting the foundation).

For retrofit of sub-standard RC b-c joints, Priestley et.al. [30] were the first to put forward the idea of reducing the joint demand forces or/and joint-prestressing. Research in USA [32] and Japan [14] have then investigated the use of joint 
prestressing/post-tensioning to improve joint shear capacities with mixed results. Hitherto, to the authors' knowledge, there is no full verification of a SW retrofit techniques for sub-standard exterior RC b-c joint as herein proposed, i.e. consisting on beam weakening and external post-tensioning.

\subsection{EXPERIMENTAL INVESTIGATION}

\subsection{Specimen details and description of SW retrofit schemes}

Four 2/3-scaled specimens of non-ductile exterior $\mathrm{RC}$ b-c joint, as part of a tenspecimen experimental program, were tested. The prototype b-c joint was designed to represent the worst typical case in pre-1970s construction practice while meeting the requirements of older building codes $[1,19]$. The exterior joint sub-assembly is assumed to be between the points of contra-flexure at mid-height of columns and mid-span of the beam within a prototype RC frame. The joint core has no transverse reinforcement and the beams longitudinal reinforcement are anchored using $180 \mathrm{deg}$. standard hooks, as shown in Figure 3a. All test units have 230mm x 230mm (9x9 inch.) columns and $330 \mathrm{~mm}$ deep x $230 \mathrm{~mm}$ wide ( $13 \mathrm{x} 9$ inch.) beams. Geometry and reinforcement details of the as-built b-c joint is shown in Figure 4a. Standard steel products are used: mild steel and pre-stressing 7-wire $12.7 \mathrm{~mm}$ diameter strands with yield strength of $330 \mathrm{MPa}(47.9 \mathrm{ksi})$ and $1560 \mathrm{MPa}(226.3 \mathrm{ksi})$ respectively. No column lap-splice or floor slab were included in this series of tests but were subsequently tested as part of the experimental program. The description of the test units are given in Table 1.

Table 1: Description of Beam-Column Joint Test Units

\begin{tabular}{|c|c|c|c|c|c|c|c|}
\hline $\begin{array}{l}\text { Test } \\
\text { Unit }\end{array}$ & Description & $\begin{array}{c}\text { Beam } \\
\text { Reinforcements } \\
\text { (top : bottom) }\end{array}$ & $\begin{array}{l}\text { PT Force, } \\
\text { kN (kips) }\end{array}$ & $\begin{array}{l}\text { Concrete } \\
\text { Strength, f'c, } \\
\mathrm{MPa}^{1} \text { (psi) }\end{array}$ & $\begin{array}{l}\mathrm{M}_{\text {beam-cal }}^{2} / \\
\mathrm{M}_{\text {column-cal }}^{3}\end{array}$ & $\underset{\mathrm{kNm}}{\mathrm{M}_{\text {beam-cal }}^{2},}$ & $\mathrm{M}_{\text {joint-cal }}{ }^{4}, \mathrm{kNm}$ \\
\hline NS-O1 & $\begin{array}{l}\text { as-built benchmark } \\
\text { specimen } \\
-50 \% \text { beam }\end{array}$ & 4-R10 : 4-R10 & - & $17.5(2538)$ & $+1.79-0.98$ & \pm 33.2 & $+10.4-15.5$ \\
\hline NS-R1 & weakening only & 4-R10 : 2-R10 & - & $25.6(3713)$ & $+0.82-0.87$ & $+15.1-29.7$ & $+10.4-15.5$ \\
\hline NS-R2 & $\begin{array}{c}+120 \mathrm{kN} \text { PT only } \\
-50 \% \text { beam weakening }\end{array}$ & 4-R10 : 4-R10 & $120(27)$ & $28.2(4090)$ & $+2.56-1.39$ & \pm 47.4 & $+12.5-21.2$ \\
\hline NS-R3 & $+40 \mathrm{kN} \mathrm{PT}$ & 4-R10 : 2-R10 & $40(9)$ & $24.3(3524)$ & $+1.26-1.07$ & $+23.4-36.3$ & $+15.4-31$ \\
\hline
\end{tabular}

Abbreviation: $\mathrm{O}=$ as-built; $\mathrm{R}=$ retrofitted; $\mathrm{PT}=$ post-tensioning; $\mathrm{R} 10=$ plain round bars with diameter $10 \mathrm{~mm}(\sim 0.4 \mathrm{in})$

${ }^{1}$ Concrete strength at the day of testing; ${ }^{2}$ Beam flexural capacity based on concrete compression strain, $\varepsilon_{\mathrm{c}}=0.003$

${ }^{3}$ Column flexural capacity at expected axial loads ${ }^{4}$ Calculated joint shear capacity based on principal tensile stresses

Positive moment corresponded to the Pull direction, where bottom of the beam is in tension. $(1 \mathrm{kNm}=737.5 \mathrm{lb}-\mathrm{ft})$

Test unit NS-O1 is the un-retrofitted as-built benchmark b-c joint. Test unit NS-R1 represents a Partial SW retrofit, where $50 \%$ of the bottom longitudinal beam bars were cut. This was done in the lab using a plate grinder (Figure $3 \mathrm{~b}$ ); while for larger specimens diamond cutters would be commercially available. The concrete gap is later re-grouted with SIKA ${ }^{\text {TM }}$ GP Grout. Test unit NS-R2 is to investigate the effect of external pre-stressing on the poorly detailed b-c joint. Test unit NS-R3 is an 
example of the Full SW retrofit scheme, where the beams are selectively weakened in conjunction with external pre-stressing of the b-c joint. The $20 \mathrm{~mm}(\sim 3 / 4$ in $)$ anchorage plate, anchored with 2 Fisher ${ }^{\mathrm{TM}} 10 \mathrm{~mm}$ ( $\left.\sim 0.4 \mathrm{in}\right)$ FAZ II anchors, is designed such that a rigid anchorage is achieved. It is expected that commercial prestressed anchorage can be used for practical applications. Only a relatively low prestressing force is required for successful joint retrofit, and from laboratory experience, this post-tensioning operation is not very labour-intensive (Figure 3c).

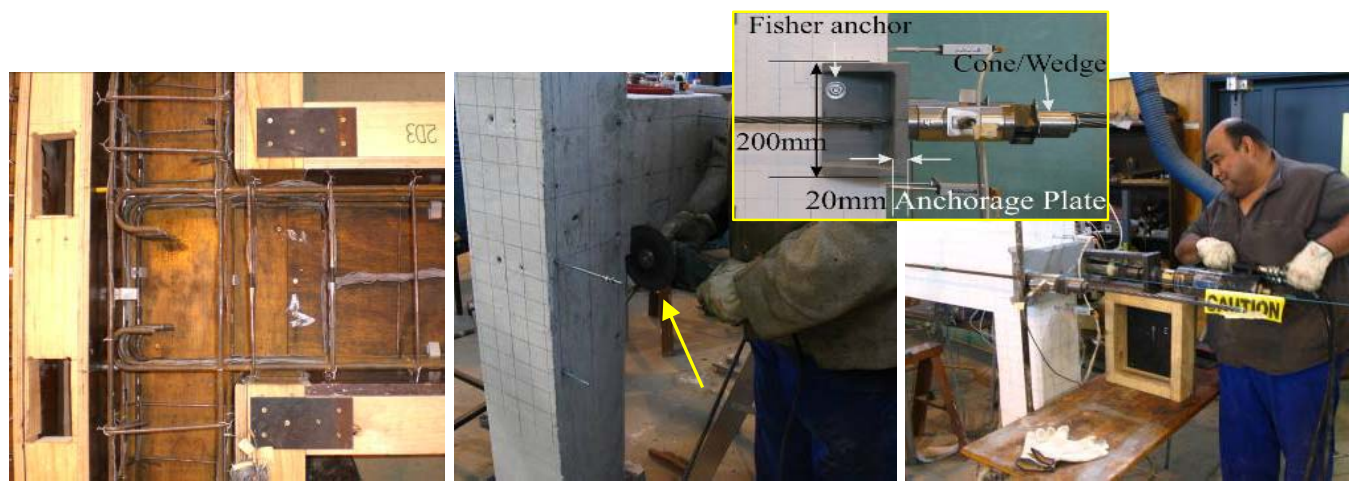

Figure 3: a) B-c joint reinforcing details b) Beam weakening - severing beam bottom longitudinal reinforcements with plate grinder (arrow) c) Applying external posttensioning on the exterior b-c joint (insert: anchorage for post-tensioning)

\subsection{Experimental test setup, loading protocol and instrumentation}

Figure 4a shows the experimental test setup. To simulate earthquake loading, cyclic quasi-static lateral loading was applied horizontally at the top of the column. The loading protocol used in this experiment consists of two displacement-controlled cycles at increasing amplitudes as follows: $0.1 \%, 0.2 \%, 0.5 \%, 1.0 \%, 1.5 \%, 2.0 \%$, $2.5 \%, 3.0 \%$ and $4.0 \%$ inter-storey drifts, as shown in Figure $4 \mathrm{~b}$.
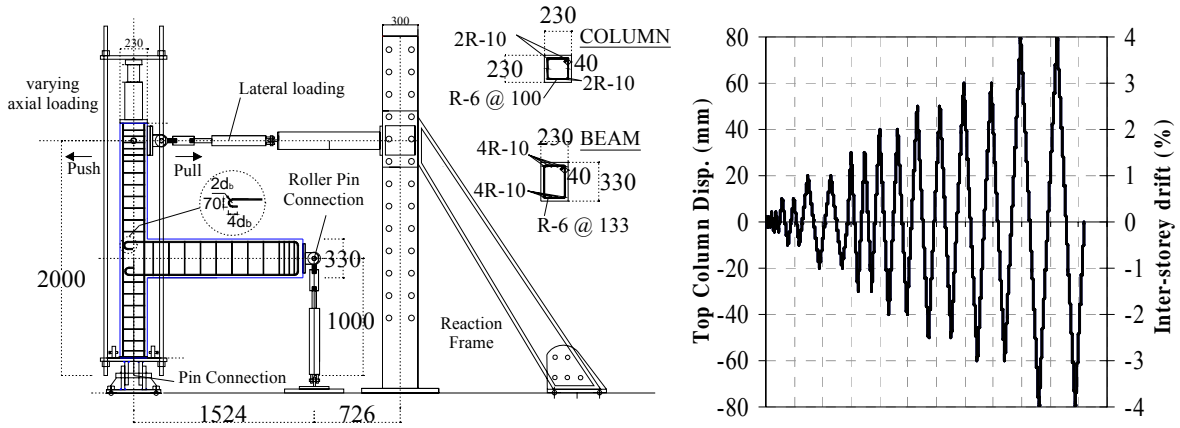

Figure 4: a) Experimental Test Setup (unit shown are in $\mathrm{mm}$ ) b) Loading Protocol

Varying axial load of $120 \mathrm{kN} \pm 4.63 \mathrm{~V}_{\mathrm{C}}\left(26.98 \pm 4.63 \mathrm{~V}_{\mathrm{C}}\right.$ in kips $)$ is implemented to account for the frame action, where $\mathrm{V}_{\mathrm{C}}$ is the lateral force applied at the top of the column. The adopted varying axial load ratio, which is function of frame geometry (bay length and number of stories) is unusually high (coefficient of 4.63), to induce the worst case scenario of very low axial (near zero) force in the exterior column / b- 
c joint. All the specimens were thoroughly instrumented to measure: a) lateral force applied b) displacement at the top of the column c) local deformation components d) strains in the reinforcement and e) manual crack widths.

\subsection{Experimental results}

The summary of the test results is presented in Table 2 and the force-displacement hysteresis responses of the four b-c joints are presented in Figure 5. The cracking and damage patterns at the end of loading at $1.0 \%$ drift and at the end of test are presented in Figure 6. All b-c joints were tested up to $4.0 \%$ cycles except for NS-O1, which failed prematurely at the end of the 2 nd cycles at $3.0 \%$ lateral drift. It is noted that the 'ultimate' failure point is defined as the level corresponding to the reduction of $20 \%$ of the original peak force within the same drift cycle.

Table 2: Summary of experimental test results

\begin{tabular}{|c|c|c|c|c|c|c|c|}
\hline Test Unit & Failure Mode & $\begin{array}{c}\text { Peak Lateral } \\
\text { Force, kN } \\
\text { (kips) }\end{array}$ & $\begin{array}{c}\text { Inter-storey drift } \\
\text { at maximum } \\
\text { force, } \theta(\%) \\
\end{array}$ & $\begin{array}{l}\text { Ultimate inter- } \\
\text { storey drift, } \theta \\
(\mathrm{rad}) \\
\end{array}$ & $\begin{array}{c}\mathrm{M}_{\text {sys-exp }}^{2}, \mathrm{kNm}(\mathrm{lb}- \\
\mathrm{ft})\end{array}$ & $\begin{array}{l}\mathrm{M}_{\text {sys-cal }}^{3}, \mathrm{kNm} \\
\quad(\mathrm{lb}-\mathrm{ft})\end{array}$ & $\begin{array}{c}M_{\text {sys-exp }} / M_{\text {sys- }} \\
\text { cal }\end{array}$ \\
\hline NS-O1 & Joint Shear Failure & $\begin{array}{c}+14.7-19.4 \\
(+3.30-4.36)\end{array}$ & $+1.97-0.96$ & $+1.0 \%-\mathrm{II}$ & $\begin{array}{c}+12.3-16.2 \\
(+9071-11947)\end{array}$ & $\begin{array}{c}+10.4-15.5 \\
(+7670-11431)\end{array}$ & $+1.18-1.05$ \\
\hline NS-R1 & $\begin{array}{l}\text { Beam Flexural, } \\
\text { Compression Anchorage }\end{array}$ & $\begin{array}{c}+8.5-15.1 \\
(+1.91-3.39)\end{array}$ & $+0.97-0.76$ & $-2.5 \%-\mathrm{II}$ & $\begin{array}{c}+7.1-12.6(+5236 \\
-9292)\end{array}$ & $\begin{array}{c}+10.4-15.5 \\
(+7670-11431)\end{array}$ & $+0.68-0.81$ \\
\hline NS-R2 & $\begin{array}{c}\text { Beam/Column Flexural } \\
\text { Hinging }\end{array}$ & $\begin{array}{c}+18.0-25.8 \\
(+4.05-5.80)\end{array}$ & $+1.77-2.0$ & $-4.0 \%-\mathrm{II}$ & $\begin{array}{c}+15.0-21.5 \\
(+11062-15855)\end{array}$ & $\begin{array}{c}+12.5-21.2 \\
(+9218-15634)\end{array}$ & $+1.20-1.01$ \\
\hline NS-R3 & Beam Flexural Hinging & $\begin{array}{r}+17.6-21.6 \\
(+3.96-4.86) \\
\end{array}$ & \pm 4.0 & -4 & $\begin{array}{c}+14.7-18.0 \\
(+10841-13274) \\
\end{array}$ & $\begin{array}{c}+15.4-31(+11357 \\
-22861) \\
\end{array}$ & $+0.95-0.58$ \\
\hline
\end{tabular}

${ }^{1}$ Failure point defined as attained peak force is less than $80 \%$ of previous peak force; ${ }^{2}$ Maximum column moment attained in the test.

${ }^{3}$ Calculated maximum column moment based on heirarchy of strength of b-c joint elements ${ }^{4}$ No failure (based on the definition) achieved.

Positive moment corresponded to the Pull direction, in which the bottom of the beam are in tension. $(1 \mathrm{kNm}=737.5 \mathrm{lb}-\mathrm{ft})$

An evaluation of the hysteresis loops in Figure 5 reveals the improved performance of all the retrofitted specimens in comparison to the benchmark NS-O1. NS-O1 experienced significant strength degradation upon the diagonal shear cracking at $1.0 \%$ drift cycles. This led to ultimate failure at the second cycle of the $1.0 \%$ drift. Very little ductility capacity was achieved for NS-O1 with failure occurring at a drift of $1.0 \%$ - in which the bottom beam longitudinal bars did not yield while the top longitudinal bars just yielded. This was expected and predicted accurately (see Table 2) using the hierarchy of strength analysis in which the joint shear capacity was estimated using the joint principal stress approach [30]. The loss of bond and pushout of the $180^{\circ}$ degree anchorage led a pinched hysteresis shape, with minimal energy dissipation. During the $1 \mathrm{st}$ cycle pushing to $2.5 \%$ drift, the column longitudinal bars began to buckle under the increasing axial load and the load carrying capacity of the b-c joint decreased significantly.

For NS-R1 ( $50 \%$ beam bottom face flexural weakening), a stable 'fat' hysteresis loop with significant energy dissipation was attained up to the 2nd Pull cycle at $2.5 \%$ lateral drift. Beam flexural hinging dominated the inelastic mechanism up to that stage before concrete spalling on the joint-column face due to the compression pushout force from the standard hook compression anchorage action. This led to NS-R1 ultimate failure at Push 2.5 2nd cycle, but the overall seismic performance of NS-R1 was much improved compared to NS-O1. The inelastic mechanism was changed and 
increased deformation and energy dissipation capacities were achieved in NS-R1. Nevertheless, upon concrete spalling in the joint face and significant bond degradation of the plain round bars, significant slip and pinching were observed in the force-displacement curves of NS-R1.
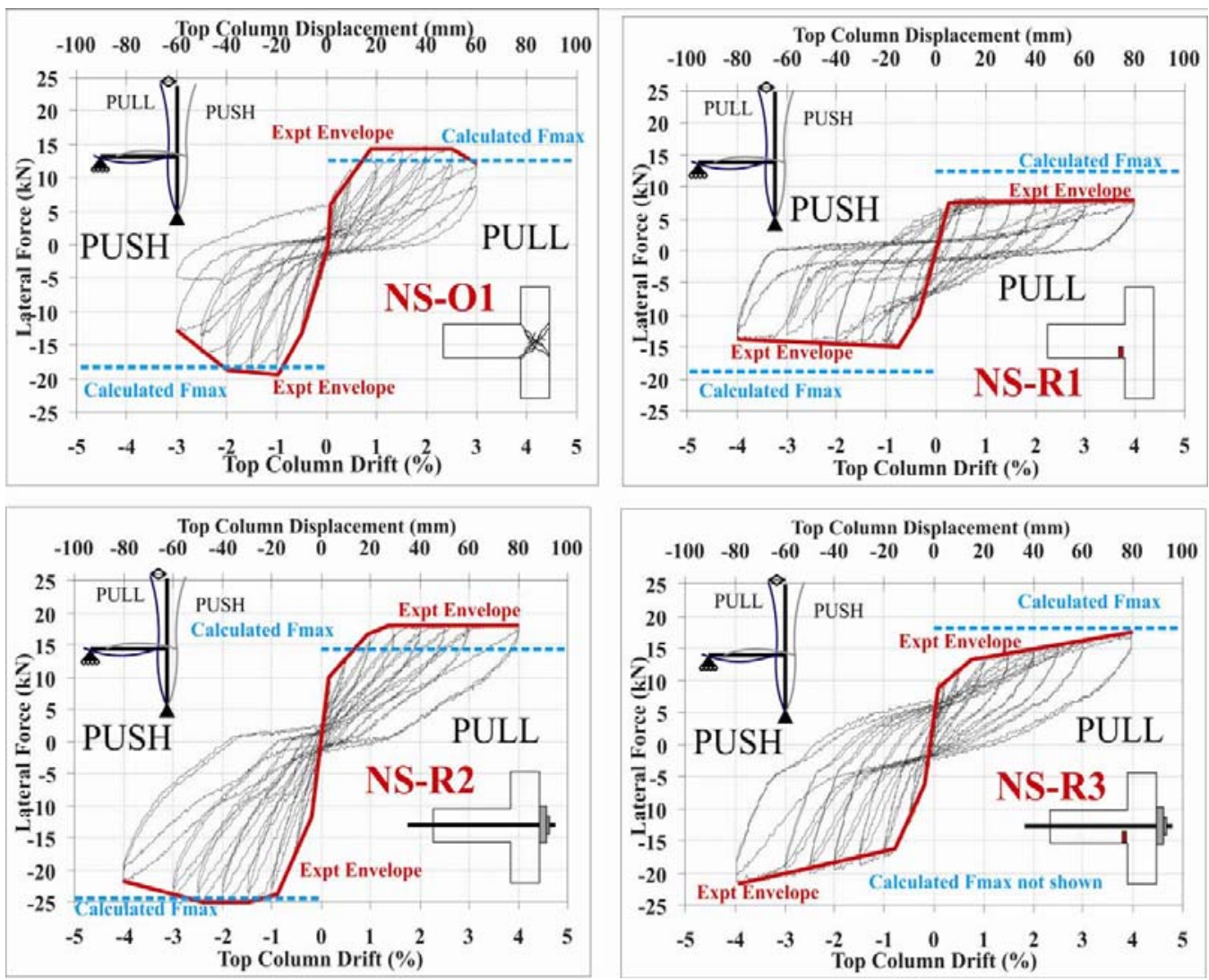

Figure 5: Experimental force-displacement hysteresis curves $(1 \mathrm{kN}=0.22482 \mathrm{kips})$

The external joint pre-stressing only retrofit was very successful in preventing the joint shear failure by increasing the tensile capacity of the joint, as demonstrated in test unit NS-R2. However, with beam-to-column flexural capacities ratio ranging between 1 and 1.8 for the prototype b-c joint, strengthening both the joint and beam would lead to column hinging; thus it validates the benefit to weaken the beam in some retrofit scenarios. Joint diagonal shear cracks appeared during the peaks of the 1 st Pull and Push cycles of the $1.5 \%$ drift, as predicted, but the added confinement from external pre-stressing prevented any strength degradation or diagonal crack growth. The final inelastic mechanism was a mixed of column fixed-end hinging and beam fixed-end hinging with some signs of column bars buckling at $4 \%$ drift cycles.

The full SW retrofitted test unit, NS-R3, performed very satisfactorily to $4.0 \%$ interstorey drift, without structural failure, strength degradation or signs of loss of vertical load-carrying capacity (e.g. column bars buckling or beam shear). The beam flexural hinging dominated the deformation up to $4.0 \%$ drift, with cracking concentrated at the weakened beam section. In the Pull direction, a stable flexural hinging with 


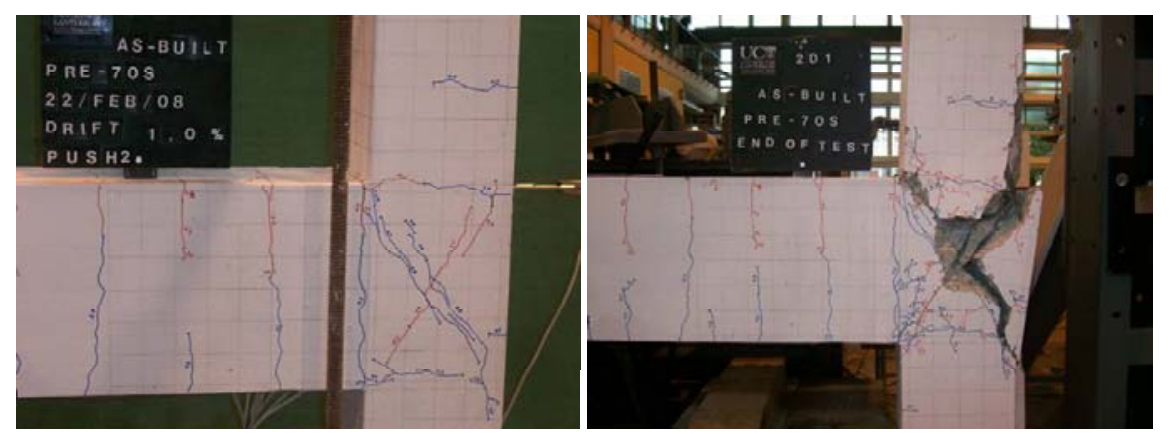

a) NS-O1: As-built benchmark b-c joint

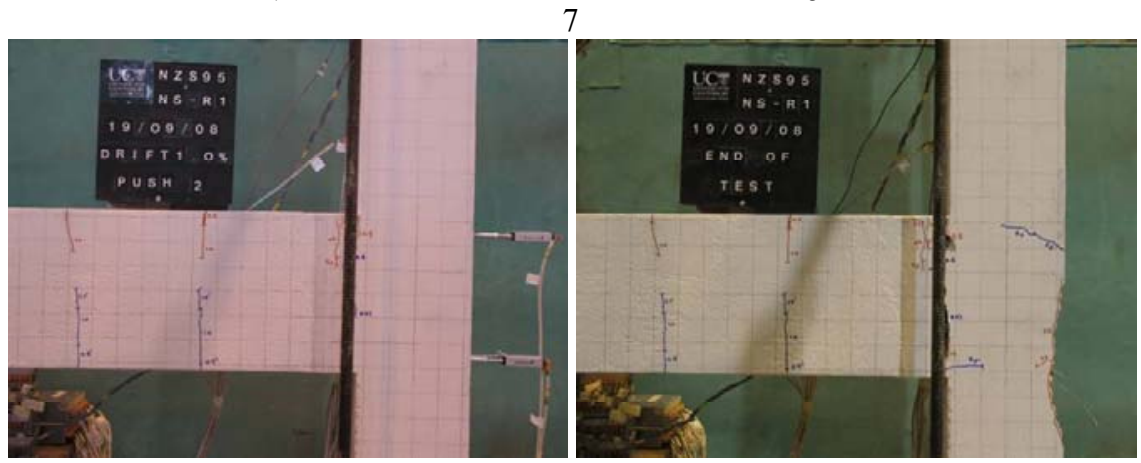

b) NS-R1: Partial Selective Weakening retrofit - $50 \%$ beam weakening

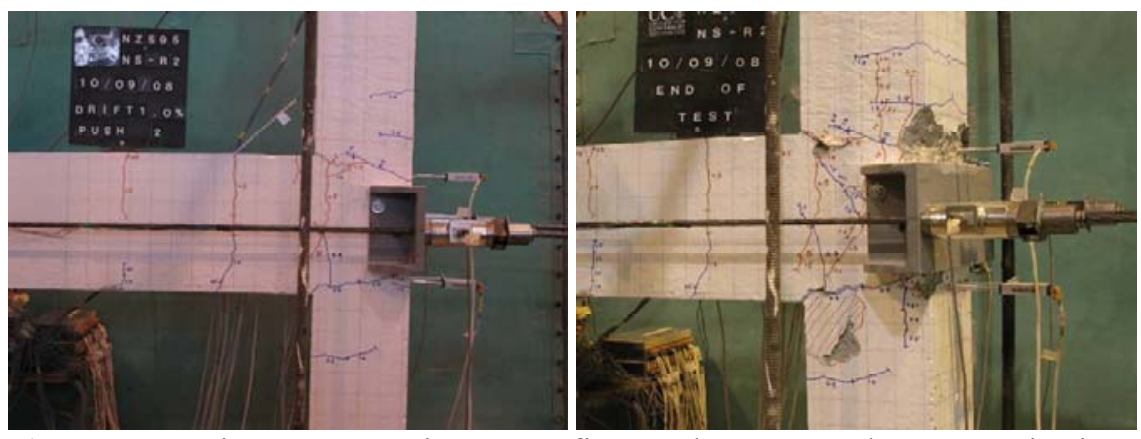

c) NS-R2: Joint Pre-stressing Retrofit- $120 \mathrm{kN}$ external post-tensioning
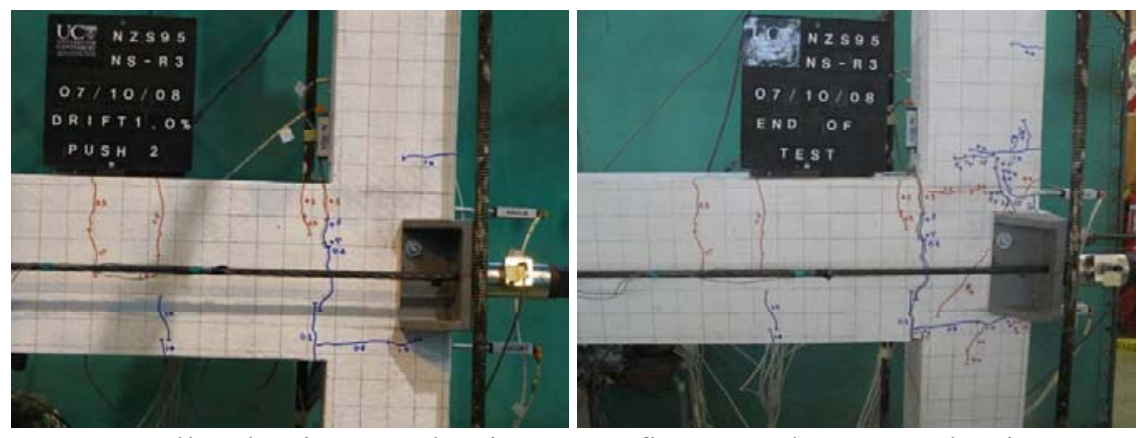

d) NS-R3: Full Selective Weakening Retrofit $-50 \%$ beam weakening $+40 \mathrm{kN}$ external post-tensioning

Figure 6 : Damage pattern at 1.0\% drift and end of test (at $4.0 \%$ drift, except for NSO1 which was tested to $3.0 \%$ ) 
considerable energy dissipation capacity was achieved. Minor pinching in the forcedisplacement hysteresis and stiffness degradation (in 2nd cycles) was observed in the Push direction as bottom beam longitudinal bars not providing any compression resistant due to the bond failure of the bars. In comparison to NS-O1, NS-R3 attained the same overall lateral force capacity as the $40 \mathrm{kN}$ external post-tensioning compensated for the $50 \%$ flexural weakening of the beam. The retrofit solution also averted joint shear failure. However, diagonal cracking was observed along the compression strut within the b-c joint, a sign that the principal compression stress might have exceeded the cracking threshold.

\subsection{ANAL YTICAL INVESTIGATION}

\subsection{Modeling approaches}

To accurately describe the mechanics underlying the exterior $\mathrm{RC}$ b-c joints behaviour, a refined finite-element (FE) 3D continuum model based on microplane concrete model with relaxed kinematic constraint on smeared crack approach [24] is used. The numerical results are compared with the experimental test results described in Section 3.0. The FE-generated and experiment-validated hysteresis behaviour of the as-built and retrofitted b-c joints are then adopted for inelastic time-history analyses of a case-study 6-storey pre-1970s RC frame using Ruaumoko2D [7]. For brevity, this paper presents selected analytical results for the NS-O1 and NS-R1 (weakeningonly) cases. Further details of the models and modelling assumptions are available in reference [17].

\subsection{Local sub assemblages FE model and quasi-static analysis}

The FE-continuum model is implemented in MASA [23], a program developed at the University of Stuttgart, incorporating a microplane concrete model. Microplane concrete model is a $3 \mathrm{D}$ macroscopic model in which the concrete is characterized by uniaxial stress and strain relationship on planes of various orientations called "microplanes" [24]. The longitudinal and transversal reinforcements are modelled using one-dimensional (1D) truss elements with phenomenological steel model [24]. The bond-slip relationship for plain round bars are also modelled using discrete bond element with 1-D constitutive relationship established from experimental data [9]. The numerical model for the benchmark NS-O1 has been developed conjointly with researchers from the University of Stuttgart [9].

Figure 7 shows the comparison of the experimental and numerical forcedisplacement curves for test units NS-O1 and NS-R1 (partial SW retrofit solution).

For the as-built b-c joint, NS-O1, the numerical model was able to capture the joint shear failure and subsequent strength and stiffness degradation quite well. The joint shear failure mode and subsequent decay of strength due to bond slip were also captured in the model. The damage pattern, as shown in Figure 8, was also accurately predicted by the MASA model, when compared to the experimental observations. However, the reinforcement bar slipping upon bond failure was not captured properly within the current model. 
While the numerical model for NS-R1 predicted correctly flexural hinging in the Pull direction, it overestimated the lateral force by $4-5 \mathrm{kN}(0.9-1.1 \mathrm{kips})$ before bondfailure and onset of slipping of reinforcement at approximately $30 \mathrm{~mm}(1.5 \% \mathrm{drift})$. On the Push direction, while the lateral force prediction is within $15 \%$ error margin for most points, the MASA model again over-estimated the bond strength of the plain round reinforcements, thus overstated the lateral force prior to joint shear cracking.
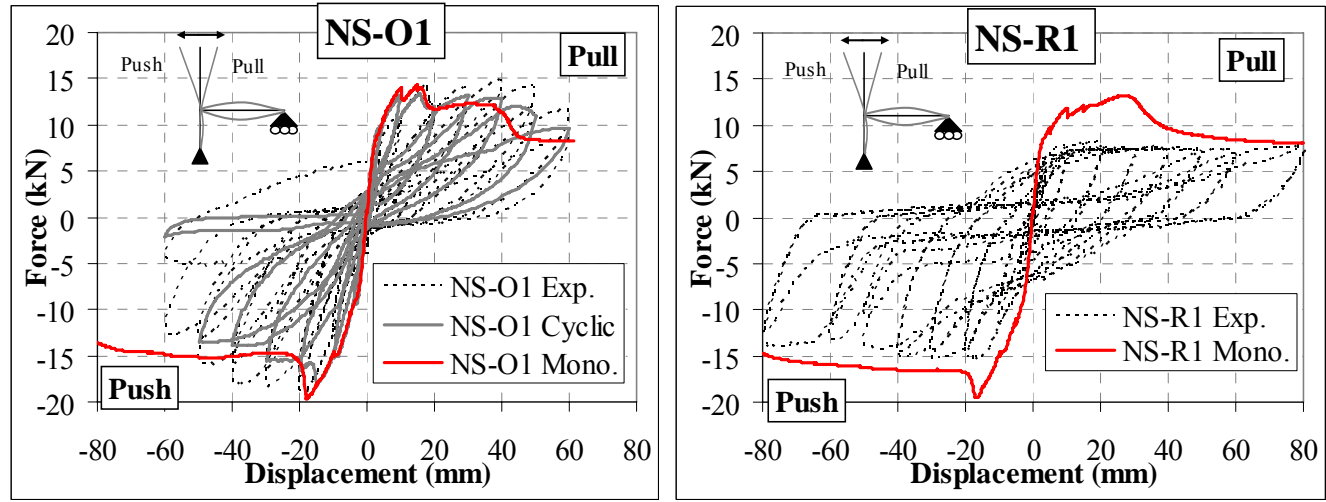

Figure 7: Comparison of experimental-numerical force-displacement curves - a) NS$\mathrm{O} 1 \mathrm{~b}) \mathrm{NS}-\mathrm{R} 1$ - partial SW retrofit solution $(1 \mathrm{kN}=0.22482 \mathrm{kips})$

The monotonic Push analyses of both models (NS-O1 and NS-R1) have indicated joint diagonal cracking at approximately $18 \mathrm{~mm}(0.9 \% \mathrm{drift})$ with minor strength degradation in subsequent drifts. This is true for NS-O1, where joint shear cracking was observed in both Pull and Push $1.0 \%$ drift cycles. However, experimentally, no joint cracking was observed until $4.0 \%$ drift cycles for NS-R1 test unit. This discrepancy, in addition to the over-prediction in the monotonic Pull analysis for NS$\mathrm{R} 1$, indicates the limitations of the current model in capturing the bond-slip of the plain round bars, while confirming the complexity of the phenomenon. For NS-R1, the concentration of bond stresses in the remaining 50\% of the longitudinal bottom beam reinforcements play significant role in the overall $b$-c joint behaviour. Cyclic analysis results of NS-R1, which might explain these differences and improve the numerical behaviour, is not available at the time of writing.

The refined FE model also generates stress-field maps, which would allow some theoretical validation on the joint shear transfer mechanics for $\mathrm{RC} b$-c joints with no or very little transverse reinforcements and smooth reinforcement steel. As shown for NS-R1: Push $1.5 \%$ in Figure 8 , upon joint diagonal cracking, a narrow diagonal compression strut [29] carries the most of the joint shear. In contrary, for NS-R1: Pull $1.5 \%$, where diagonal cracking has not occurred, the shear stress is distributed over a broader band of diagonal compression field (despite having no joint stirrups to complete the truss mechanism [29]). The analysis result also indicates that the bond strength of the reinforcements embedded within the joint deteriorates rapidly upon joint diagonal cracking, consistently with the strain readings from the experimental results [17]. 

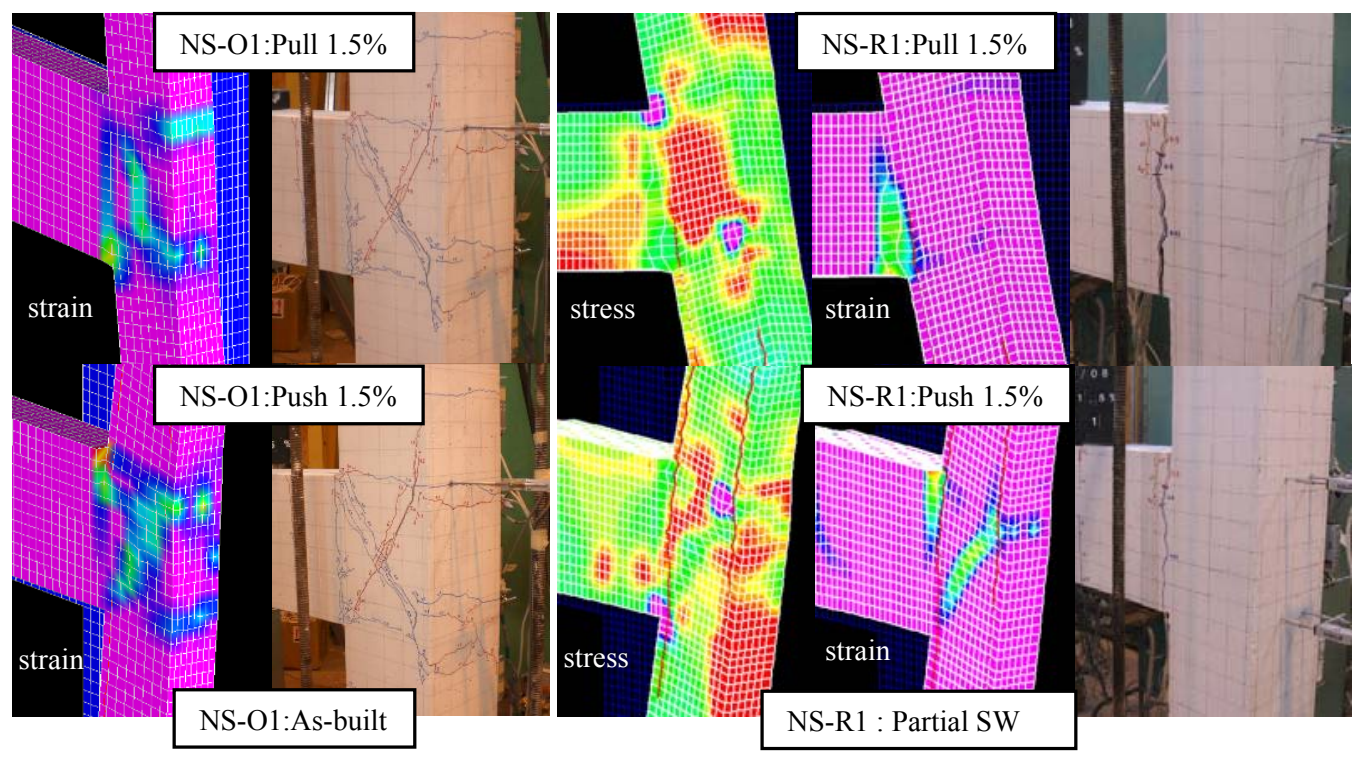

Figure 8: Predicted (strain and stress of FE elements) and observed failure mode and cracking pattern of NS-O1 and NS-R1 (partial SW Retrofit) b-c joint.

\subsection{Global macro-FE model and time history analysis}

The pre-1970s non-ductile RC frame prototype consists of a six-storey, three-bays $(4.5 \mathrm{~m}-2.5 \mathrm{~m}-4.5 \mathrm{~m})$, inter-storey height of $3 \mathrm{~m}$ and of typical pre-1970s construction details [13]. Lumped-mass and -plasticity modelling are adopted, where inelastic deformations are limited to discrete inelastic rotational springs in the joints and beams and columns. Two rotational joint springs with appropriate 'pinching' hysteresis rule which includes cyclic strength and stiffness degradation are used to model the joint panel zone of existing RC frame as suggested by [28]. Thin modified Takeda hysteresis $(\alpha=0.5, \beta=0)$ are used for to model flexural hinges in beam and column elements. Shear inelastic deformation is not modelled as preliminary analysis indicates flexural action would dominate in both columns and beams in these pre1970s gravity-designed RC frames. The retrofitted RC frame utilises a partial retrofit intervention with weakened-beam-only (NS-R1) scheme at the exterior b-c joints.

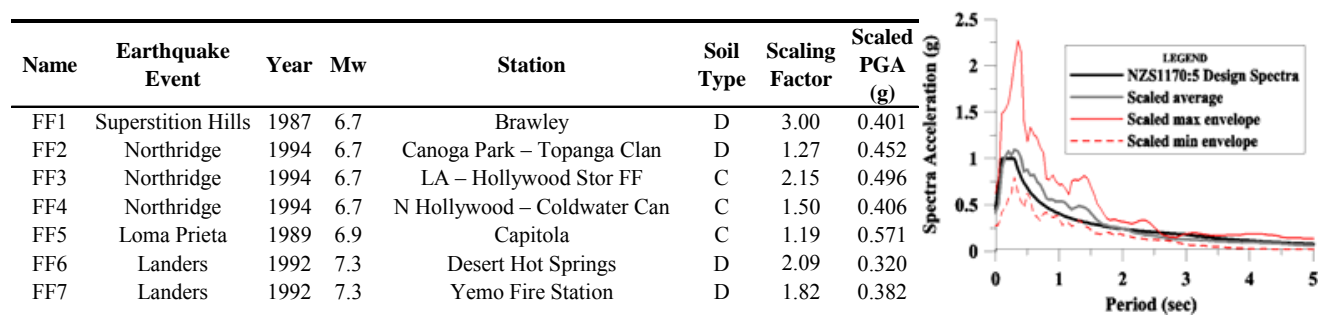

Figure 9: Characteristics of the scaled earthquake records and acceleration spectra

The inelastic time-history analyses are carried out using finite-element program Ruaumoko2D [7]. A Newmark-beta integration scheme with a 5\% Rayleigh damping model proportional to the tangent-stiffness was adopted. Seven historical strong 
ground motion records without directivity effects, scaled to the recommendations of NZS1170:5 [20] were used. The characteristics of the scaled earthquake records and the scaled acceleration spectra are presented in Figure 9.

Figure 10 presents the envelopes of the maximum responses from the non-linear time history analyses of a pre-1970 designed RC frame. As expected, the as-built frame has limited energy dissipation capacity with shear failures occurring within the b-c joints. Joint rotation is the predominant inelastic mechanism with the average joint rotations exceeding 0.018 radians, indicating incipient collapse. In addition, with inter-storey drift exceeded typical damage limit states $(\sim 2-2.5 \%)$, indication of softstorey collapse at level 4 (with inter-storey drift $>3.5 \%$ ). The as-built frame is more likely to collapse as the rotation and curvature demands on the joints and columns respectively were all exceeding the typical collapse limit states.

Meanwhile, for the NS-R1 (Partial SW) retrofitted RC frame, the average interstorey drift envelope is reduced along the building height, particularly at the level 4 . The predominant inelastic mechanism for retrofitted frame is beam flexural hinging. Even with pre-1970s detailing, the flexural hinges of RC beams have some ductility and energy dissipation capacities, especially when compared to a joint shear failure mechanism. By evaluating the average global deformation components of the retrofitted frame, one can conclude that a simple partial retrofit solution such as NSR1 can effectively prevent collapse and save lives.

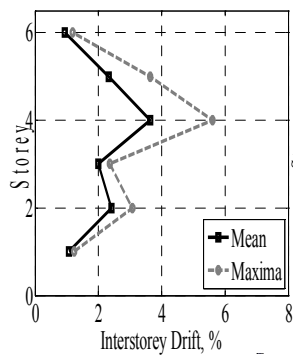

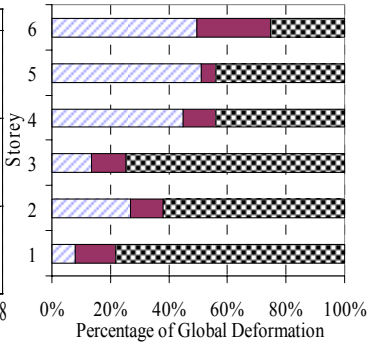

$\square$ Column Deformation

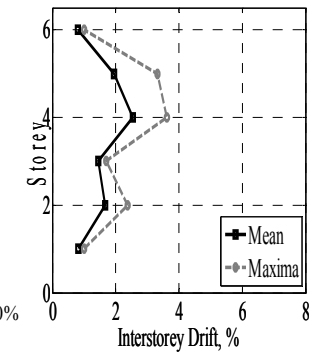

$\square$ Beam Deformation

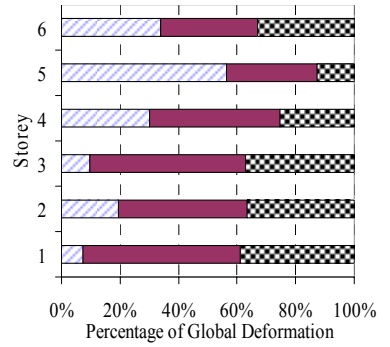

Joint Deformation

Figure 10: Average of peak inter-storey drift envelopes responses and average global deformation components of the existing and retrofitted frames.

\subsection{CONCLUSIONS}

This paper has presented the preliminary experimental and numerical validations that support the concept of SW retrofit for non-ductile (pre-1970s design) RC frames. By a) selectively weakening the beam of exterior joints (NS-R1), b) upgrading the b-c joints using external pre-stressing (NS-R2) or both a) and b) (NS-R3), the joint panel zone is protected and an improved inelastic mechanism is activated. In comparison to the benchmark (as-built) b-c joint, NS-O1, an improved performance is achieved in all SW retrofit solutions when tested experimentally. The fracture mechanics-based FEM models of the test units have also shown good approximation and valuable integration of the experimental results. This refined FE model will provide the basis for further parametric analysis. Using the local b-c joint sub-assemblages hysteresis behaviour within a non-linear dynamic analysis, the effectiveness of the SW retrofit 
for non-ductile RC frames is illustrated. It is expected that selective weakening retrofit will be part of the toolbox available to structural engineers when tackling the problem of seismic rehabilitation. With its economical, non-invasive and lowtechnology intensity approach, it is envisioned that SW retrofit could have a wide implementation potential in a macro-scale retrofit scheme.

\section{ACKNOWLEDGEMENTS}

This research is part of NZ FRST-funded project "Retrofit Solutions for NZ" www.retrofitsolutions.org.nz (FRST Contract UOAX0411). Special thanks to $\mathrm{Mr}$ Mosese Fifita, who assisted in the construction and testing of the specimens. The technical support from Prof. Joško Ožbolt (author of MASA) and Ing. Giovacchino Genesio (University of Stuttgart) is also gratefully acknowledged.

\section{REFERENCES}

[1].ACI318-63. Building code requirements for reinforced concrete (ACI318-63). Detroit: American Concrete Institute; 1963.

[2].ASCE-SEI-41-06. Seismic rehabilitation of existing buildings. Reston, Va.: ASCE/SEI; 2007.

[3].Aycardi LE, Mander JB, Reinhorn AM. Seismic resistance of R.C. frame structures designed only for gravity loads: Experimental performance of subassemblages. ACI Structural Journal. 1994;91(5):552-63.

[4].Beres A, Pessiki S, White R, Gergely P. Implications of experimental on the seismic behaviour of gravity load designed RC beam-column connections. Earthquake Spectra. 1996;12(2):185-98.

[5].Bracci JM, Reinhorn AM, Mander JB. Seismic resistance of reinforced concrete frame structures designed for gravity loads: Performance of structural systems. ACI Structural Journal. 1995;92(5):597-609.

[6].Calvi GM, Magenes G, Pampanin S. Experimental test on a three storey RC frame designed for gravity only (Paper No 727). Proc. of Proc of 12th European Conference of Earthquake Engineering; 2002; London, UK, Elsevir Science Ltd, 2002.

[7].Carr A. RUAUMOKO2D - The Maori God of Volcanoes and Earthquakes. Christchurch, New Zealand: University of Canterbury; 2008. p. Inelastic Analysis Finite Element program.

[8].CEN. Eurocode 8 - Design of structures for earthquake resistance - Part 3: Assessment and retrofitting of buildings. Brussels: Comite Europeen de Normalisation; 2006 January 2006.

[9].Eligehausen R, Genesio G, Ožbolt J, Pampanin S. 3D analysis of seismic response of RC beam-column exterior joints before and after retrofit. Proc. of ICCRRR2008; 2008; Cape Town, South Africa, 2008.

[10].FEMA-356. Pre-standard and commentary for the seismic rehabilitation of buildings. Washington, D.C.: Federal Emergency Management Agency.; 2000.

[11].fib. Seismic assessment and retrofit of reinforced concrete buildings: State-of-the-art report, fib Bulletin no. 24. Lausanne, Switzerland: International Federation for Structural Concrete (fib); 2003.

[12].FRST Retrofit. solutions for New Zealand. [Website] 2009 [cited 25th July 2009]; Available from: http://www.retrofitsolutions.org.nz/index.shtml

[13].Galli M. Evaluation of the seismic response of existing r.c. frame buildings with masonry infills [M.E.E.]. Pavia, Italy: Istituto Universitario di Studi Superiori; 2007.

[14].Hamahara M, Nishiyama M, Okamoto H, Watanabe F. Design for shear of prestressed concrete beamcolumn joint cores. ASCE Journal of Structural Engineering. 2007;133(11):1520-30.

[15].Ireland MG, Pampanin S, Bull DK. Experimental investigations of a selective weakening approach for the seismic retrofit of r.c. walls. Proc. of NZSEE Conference 2007; 2007; Palmerston North, NZ, 2007.

[16].Jensen J, Bull DK, Pampanin S. Experimental investigation of existing hollowcore seating connection: Seismic behaviour pre and post retrofit intervention. Proc. of NZSEE Conference 2007; 2007; Palmerston North, NZ., NZSEE, 2007.

[17].Kam WY. Performance-based selective weakening seismic retrofit for R.C. structures (in preparation) [PhD dissertation]. Christchurch: University of Canterbury; 2010.

[18].Kam WY, Pampanin S. Selective weakening techniques for retrofit of existing reinforced concrete structures. Proc. of 14th World Conference on Earthquake Engineering; 2008 12-17 Oct 2008; Beijing, China, 05-03-0074, 2008.

[19].NZS95:1955. New Zealand Standard - Model Building By-Laws: Part IV and V. Wellington, New Zealand: New Zealand Standard Institute; 1955. 
[20].NZS1170. NZS 1170.5:2004 Structural design actions. Wellington, NZ: Standards New Zealand; 2004.

[21].NZS3101:2006. NZS 3101:2006 Concrete structures standards. Wellington, NZ: Standards NZ; 2006.

[22].NZSEE. Assessment and improvement of the structural performance of buildings in earthquakes. Wellington, New Zealand: New Zealand Society for Earthquake Engineering (NZSEE); 2006.

[23].Ožbolt J. MASA3 - Finite element program for 3D nonlinear analysis of concrete and reinforced concrete structures Stuttgart: Institut fur Werkstoffe im Bauwesen, University of Stuttgart; 2008. p. 53 pp.

[24].Ožbolt J, Li Y, Kozar I. Microplane model for concrete with relaxed kinematic constraint. International Journal of Solid and Structures. 2001;38(16):2683-711.

[25].Pampanin S. Controversial aspects in seismic assessment and retrofit of structures in modern times: Understanding and implementing lessons from ancient heritage. Proc. of NZ Concrete Society 2005 Conference; 2005; Auckland, New Zealand, 2005.

[26].Pampanin S. Controversial aspects in seismic assessment and retrofit of structures in modern times: Understanding and implementing lessons from ancient heritage. Bull of New Zealand Soc of Earthquake Eng. 2006 June 2008;39(2):120-33.

[27].Pampanin S, Christopoulos C. Non-invasive retrofit of existing RC frames designed for gravity loads only. Proc. of fib2003 Symposium on Concrete Structures in Seismic Region; 2003; Athens, Greece, Paper No. 170, 2003.

[28].Pampanin S, Magenes G, Carr A. Modelling of shear hinge mechanism in poorly detailed RC beam-column joints. Proc. of Fib Symposium on Concrete Structures in Seismic Regions 2003; 2003; Athens, Federation International du Beton, 2003.

[29].Paulay T, Priestley MJN. Seismic design of reinforced concrete and masonary buildings. Christchurch, New Zealand: John Wiley \& Sons Inc.; 1992.

[30].Priestley MJN, Seible F, Calvi GM. Seismic design and retrofit of bridges. NY: John Wiley \& Sons Inc.; 1996.

[31].SESOC-NZSEE-NZCS. Seismic performance of hollow core floor systems - Guidelines for design assessment and retrofit (Preliminary draft - April 2009). Wellington, NZ: Department of Building and Housing; 2009.

[32].Sritharan S, Priestley MJN, Seible F. Enhancing seismic performance of cap beam-column bridge joints using prestressing. PCI Journal. 1999;44(4):74-91. 